\title{
Medicine, human rights and ethics: paths to universal rights
}

\author{
Andreas Frewer - Markus Rothhaar
}

Published online: 27 April 2010

(C) Springer Science+Business Media B.V. 2010

The core of global practical ethics consists in the international adherence to human rights. The medical and healthcare communities stand at the forefront of fundamental challenges. In 2008 the 60th anniversaries of the "Universal Declaration of Human Rights" and the "Declaration of Geneva" adopted by the World Medical Association were celebrated.

In September 1948, the Second General Assembly of the World Medical Association adopted in Geneva a declaration on the ethics of the medical profession as an up-to-date "revision of the Hippocratic Oath." The Declaration of Geneva thus became one of the most important sources for medical ethics, and an integral part of the professional code for medical personnel. Only weeks later-on December 10th 1948 - the "Universal Declaration of Human Rights" was promulgated by the General Assembly of the United Nations in the Parisian Palais de Chaillot as the foundation for international humanitarian law. Article 11 postulated: "All human beings are born free and equal in dignity and rights." The historical proximity of the two declarations was no accident; both were clearly reactions to the violations of human rights and human dignity under the National Socialist regime from 1933 to 1945.

Ever since, the "Universal Declaration of Human Rights" has been the basis for international humanitarian law and served to give lasting protection to the individual. Health is an essential requirement for the UNO's aims of

\footnotetext{
A. Frewer $(\square) \cdot$ M. Rothhaar

Institut für Geschichte und Ethik der Medizin, Friedrich-

Alexander-University Erlangen-Nuremberg, Glueckstr. 10, 91054 Erlangen, Germany

e-mail: andreas.frewer@ethik.med.uni-erlangen.de

M. Rothhaar

e-mail: markus.rothhaar@ethik.med.uni-erlangen.de
}

peace and security. With the principles of freedom, equality, justice and human dignity, bedrock values of medicine and ethics are formulated in the declaration as well. However, medicine has also been closely associated with historical and moral wrongdoing: the supposedly idealistic concepts of "eugenics" and "euthanasia," which belonged to the core doctrines of National Socialism, were originally developed in medical discourse. The "outer" war begun in 1939 by the National Socialist regime was supplemented by the murderous actions of a "eugenically" conceived "inner" war in which many physicians were involved. Observers of the Nuremberg Doctors' Trial rightly chose the expressions "medicine without humanity" and "science without humanity" when they characterized the participation of doctors in these crimes. The complete destruction of the central moral concepts of respect for the person and his or her dignity made it necessary to newly formulate the notions of human rights and humanity for the international community.

The focus of the present issue will be questions of medicine and ethics in their relation to human rights. From the broad spectrum of relevant problems, a select few have been chosen to highlight these themes. The essay by Markus Rothhaar (2010) sheds light on the topic of "Human Dignity and Human Rights in Bioethics." He looks closely at the numerous debates on human dignity and human rights from an ethical perspective. Standing front and center of his piece is Immanuel Kant's conception of human dignity as well as the Principle of Rights and Duties. By concentrating on the question of "Who Has Human Dignity?" the essay analyzes the debates on deontology and medical ethics in view of answers given by Kant as well as by later thinkers.

The second essay "Human Rights from the Nuremberg Doctors Trial to the Geneva Declaration" (Frewer 2010) 
gives broad scope to the historical context of the time after the Second World War. It shows how problems were perceived in 1948, as well as the roots and consequences of such perception. Developmental trends are analyzed on the basis of significant personalities and central documents. The attitudes of leading figures in medical ethics and humanitarian aid illustrate the history, the adoption of codices reveal the ethical content. Central passages from key documents like the "Nuremberg Code of Medical Ethics" that resulted from the Doctors' Trial, or the "Bad Nauheim Declaration" are presented and their meaning interpreted. At the international level the debate surrounding medicine's basic values culminated in the adoption of a "new Hippocratic Oath": The Geneva Declaration of the World Medical Association was seen as the "Serment d'Hippocrate, Formule de Geneve" (Oath of Hippocrates, Formulation of Geneva).

The ethical commitments of a professional group are unfortunately no guarantee that human rights will be observed. The relation between doctor and patient poses difficult and often very specific questions about human rights because of the almost inescapable difference in knowledge and power between them, as well as the vulnerability of the patient. In the second half of the twentieth century, just as in the present there are plenty of practical problems in which medical professionals are duty-bound to human rights in a special way. Two international examples are examined by the following essays.

The third contribution by Kertin Krása (2010) discusses ethical and legal problems with respect to the practiceregrettably wide-spread globally — of female genital mutilation (FGM). The article discusses first the basic notion of "female genital cutting," and then the statutory regulation, the manner of treating the issue in the course of medical training as well as the ethical guidelines for the regulation of this delicate topic. The essay depicts how this procedure that injures the health and the personality of the individual is dealt with, as well as offering a comparison between Germany and other European countries.

The fourth essay (Furtmayr and Frewer 2010) discusses questions of torture, human rights violations and the responsibility of medical personnel. Torture is a human rights problem with a long history, and even today the practice is wide-spread-perhaps even on the rise-in over 80 countries throughout the world. Holger Furtmayr and Andreas Frewer present the "Istanbul Protocol," the handbook of the United Nations for the effective investigation and documentation of torture and other inhuman forms of treatment or punishment. In the context of a larger edition project associated with the Chair of Ethics in Medicine at the University of Erlangen-Nuremberg, this manual has been translated into German for the first time and supplemented with a volume of international commentary.
This provides medical and legal experts as well as other affected groups with improved documentation of allegations and acts of torture. Prevention through documentation is a primary goal of this handbook. Important questions arise internationally about the medical documentation of torture survivors, whether in the context of the treatment of such survivors or with respect to recommendations in the course of asylum proceedings.

The contributions collected in this thematic issue on "Medicine, Human Rights and Ethics" were prepared by colleagues at the "Forum for Medicine and Human Rights" at the University of Erlangen-Nuremberg. The city of Nuremberg has special significance for the history of human rights. Episodes from the National Socialist period such as the party congresses and the race laws issued there are well-known. After the war, the "Nuremberg Trials" were intended to make the political perpetrators accountable for their crimes. The "Nuremberg Doctors' Trial" was the first criminal prosecution of a specific profession. The judgments from Nuremberg coupled with the "crimes against humanity" uncovered there, as well as the Declaration of Human Rights have had the consequence that people could and can be made responsible for their actions, even if it concerns severe offences with international participation or "inhumanity" difficult to punish; the responsibility cannot be shifted onto the state or some other authority. Instead, the protection of human rights stands front and center. The Nuremberg tribunals were also the model for the International Criminal Count at Den Haag.

More recently, Nuremberg as the "City of Human Rights" has spearheaded numerous initiatives for supporting and reinforcing the idea of human rights. A Chair of Human Rights is planned for the Friedrich-AlexanderUniversity Erlangen-Nuremberg, alongside the "Forum for Medicine and Human Rights" established in 2006 at the Professorship for Medical Ethics.

December 10th, the international "Day of Human Rights" reminds us of the promulgation of the "Universal Declaration of Human Rights" as a milestone of 1948. The "Declaration of Geneva" applies the same values, upheld by the World Medical Association and the international community, to the area of medicine. The dignity of manespecially as a patient in medical care or as test subject in research experimentation - and his status as legal subject must also be more forcefully brought to bear on the international level.

Acknowledgments We would like to thank our colleagues associated with the Chair for Ethics in Medicine and the "Forum for Medicine and Human Rights" for their productive cooperation. Thanks also to Rector Prof. Dr. Karl-Dieter Grüske and Chancellor Thomas Schöck from Friedrich-Alexander-University ErlangenNuremberg as well as Prof. Dr. Bernhard Fleckenstein, Prof. Dr. Juergen Schuettler, and Dr. Esther Schnetz from the Office of the Dean 
of the Medical Faculty for their support of the "Forum for Medicine and Human Rights" and the Chair for Ethics in Medicine. We would like to thank Prof. Dr. Heiner Bielefeldt, the Director of the German Institute for Human Rights in Berlin, and Dr. Norman Weiß from the Human Rights Center in Potsdam for their excellent professional cooperation. Special thanks to Michael McGettigan for parts of the translation. Further, we would like to thank the editors of the journal "Medicine, Health Care and Philosophy" as well as Dr. Pekka Louhiala (Helsinki) und Prof. Bert Gordijn (Dublin) for their fruitful cooperation in giving shape to the present volume of the journal.

\section{References}

Frewer, A. 2010. Human rights from the nuremberg doctors trial to the Geneva Declaration. Medicine, Health Care and Philosophy 13.

Furtmayr, H. and A. Frewer. 2010. Documentation of torture and the "Istanbul Protocol"-Applied medical ethics. Medicine, Health Care and Philosophy 13.
Krása, K. 2010. Human rights for women: The ethical and legal discussion about Female Genital Mutilation in Germany in comparison with other Western European countries. Medicine, Health Care and Philosophy 13.

Rothhaar, M. 2010. Human dignity and human rights in bioethics-the Kantian approach. Medicine, Health Care and Philosophy 13. 